\title{
Desenvolvimento projetual de dispensador eletrônico de medicamentos para idosos com doença de Alzheimer
}

\author{
DOS SANTOS RAMOS, Silvana; Graduação; Centro Universitário Ritter dos Reis \\ silr.22@gmail.com \\ Orientador: PANTOJA GIULIANO, Carla; Doutora em Design; Centro Universitário Ritter dos \\ Reis \\ carla_giuliano@uniritter.edu.br
}

\begin{abstract}
Palavras-Chave: Design de Produto. Doença de Alzheimer. Metodologia Projetual. Dispensador Eletrônico.
\end{abstract}

\begin{abstract}
Resumo: A doença de Alzheimer se caracteriza pelo declínio funcional da cognição, e seu sintoma mais evidente é a perda da memória recente. Nos últimos anos, a incidência da doença vem crescendo no mundo, na mesma proporção em que aumenta a população com mais de 65 anos. Considerando a carência de produtos destinados a esse público, o presente artigo apresenta o desenvolvimento projetual de um dispensador eletrônico de medicamentos para idosos com doença de Alzheimer em estágio inicial de demência. Trata-se de pesquisa com enfoque qualitativo e aplicativo, classificada em bibliográfica e exploratória, seguindo a metodologia de projeto dos autores Bonsiepe (1986), Löbach (2001) e as ferramentas de desenvolvimento projetual do HCD IDEO (2009) para compreender as necessidades do usuário. 0 produto proposto pretende auxiliar o idoso a administrar sua medicação, permitindo-Ihe autonomia, assim como visa ajudar cuidadores e familiares a organizar e controlar o consumo da medicação do doente.
\end{abstract}

\section{Introdução}

As demências compõem um grupo de doenças evidenciadas por distúrbios neurológicos. Elas acometem principalmente os idosos e geram impacto para o sistema de saúde e a previdência social (BERTOLUCCI, 2003). A doença de Alzheimer se caracteriza pelo declínio funcional da cognição; seu início é insidioso, e o sintoma mais evidente é a perda da memória recente. Nos pacientes com a condição, é possível observar, entre outros sinais, redução da capacidade cognitiva. (CARAMLLI E BARBOSA, 2002). De acordo com a Associação Brasileira de Alzheimer (Abraz), podem ser observados três estágios da doença de Alzheimer: leve, moderado e avançado. Em alguns casos, a evolução dos sintomas é lenta, o que possibilita a manutenção de níveis funcionais razoáveis por muitos anos; em outros, porém, a deterioração é rápida, embora ocorra em velocidade constante.

Considerando todas as implicações que envolvem a doença de Alzheimer, o presente artigo trata do desenvolvimento projetual de um dispensador eletrônico de medicamentos para idosos com o distúrbio em estágio leve. O produto pretende auxiliá-los a administrar sua medicação, permitindoIhe autonomia.

\section{Metodologia do projeto}

Este trabalho possui enfoque qualitativo e aplicativo, que, segundo Gil (2010, p. 133), auxilia no norteamento do problema. Na busca de maior familiarização com a temática, o projeto teve início em pes- 
quisa bibliográfica e, por meio dela, foi possível conhecer e analisar informações sobre os idosos que sofrem de doença de Alzheimer. Além disso, foram realizadas entrevistas com profissionais, como técnicos de enfermagem, cuidadores, médicos neurologistas e farmacêuticos. Os relatos mais recorrentes dizem respeito a declínio cognitivo, sobretudo no que se refere a comportamento.

$\mathrm{Na}$ abordagem metodológica projetual, utilizou-se Bonsiepe (1986), Löbach (2001) e ferramentas de desenvolvimento projetual do Human centered design - HCD IDEO (2009). As análises sincrônica, funcional e estrutural foram realizadas de acordo com os processos de Bonsiepe (1986) e adaptadas conforme a relevância do projeto. Concomitante às análises, realizou-se imersão no ambiente em que vivem alguns idosos, seguindo os princípios do HCD IDEO (2009), para observar as reais necessidades dos usuários e verificar suas possíveis limitações. Essa etapa foi realizada em asilo localizado em Porto Alegre/RS. Nessa fase, foi possível acompanhar a rotina de uma idosa com a doença. O contato foi importante para verificar como a doença de Alzheimer influencia a vida dos idosos e para perceber como atividades rotineiras podem ser difíceis de se executar. Muitos necessitam de cuidados diários, pois apresentam dificuldade de entender o que está acontecendo, de diferenciar o dia da noite, o frio do quente, assim como de se orientar.

Realizadas as análises dos dados, desenvolveu-se uma lista com requisitos, conforme a metodologia de Bonsiepe (1986), que serviu para orientar o processo projetual em relação às metas a serem atingidas. No decorrer do projeto, foram criados conceitos e alternativas e definidas as qualidades desejáveis para o produto. Na etapa final, foi detalhada a alternativa - com desenhos técnicos e modelos virtuais - que mais se adaptou aos objetivos e aos requisitos do produto. Também foi construído um modelo físico funcional, utilizando recursos de impressão 3D e plataformas robóticas de baixo custo, como a placa open-hardware Arduino.

\section{Resultado Projetual}

Para a realização do projeto, foram considerados fatores ergonômicos, antropométricos e estéticos. Optou-se pela alternativa que, segundo Norman (2004, p.50), pode gerar afeto positivo, como rostos sorridentes, objetos simétricos, lisos e arredondados. Além disso, buscou-se aplicar o conceito de affordance, visando boa usabilidade nas interações, a partir de aspectos como percepção e ação. (GIULIANO, 2014)

O dispensador eletrônico é um organizador de medicamentos programável (Figura 1), projetado para ejetar medicações de forma autônoma. Na parte superior, encontra-se o disco de medicamentos removível, que contém 24 compartimentos; nele, é possível acomodar cerca de 10 pílulas de tamanho padrão em cada compartimento. Conforme programado, o disco gira no sentido horário, e o remédio é depositado na bandeja, localizada na parte inferior do produto, na hora desejada. Além do produto, o dispensador acompanha os seguintes itens: manual de instruções, cartelas móveis, que indicam dia da semana e o período do dia, um software nativo e um carregador com conexão USB. 


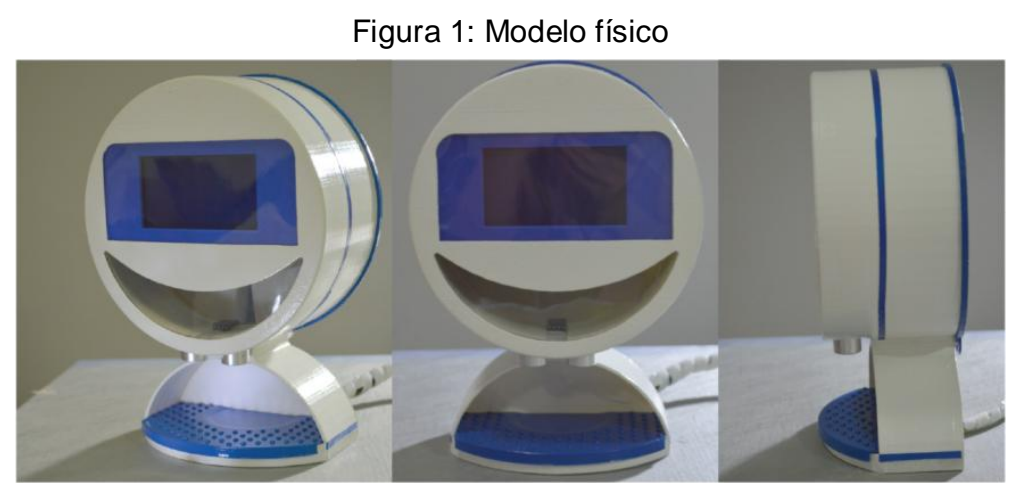

Fonte: Elaborada pela autora, 2016.

É previsto o uso de cores, avisos sonoros, avisos visuais para melhor interação entre o usuário com o produto. A colocação do medicamento e o ajuste de alarmes são atividades do usuário secundário, ou seja, do familiar ou cuidador. A principal ação a ser realizada pelo usuário primário, ou melhor, pelo idoso com doença de Alzheimer em estágio leve, será apenas retirar o medicamento no local indicado.

\section{Considerações finais}

Finalizadas todas as etapas da metodologia de desenvolvimento de produtos, conclui-se que o dispensador eletrônico de medicamentos atendeu aos objetivos pretendidos pelo projeto. Neste estudo, pôdese não apenas consolidar o conhecimento científico acerca da demência, mas também pôr em prática as etapas de desenvolvimento projetual. Com base nisso e com o intuito de promover melhoria à qualidade de vida de idosos com a doença e de seus familiares e cuidadores, o produto possibilita autonomia para os idosos e monitoramento para os familiares. Ao proporcionar orientação temporal aos pacientes com a doença, o dispensador também promove estímulos cognitivos.

A solução final representa um produto que atende à delimitação inicial do projeto, sobretudo no que se refere ao público-alvo. O projeto pode ser ampliado e adaptado a pessoas com deficiências visuais, pois auxiliaria a informar o tipo de medicação que o paciente irá ingerir, assim como os orientaria temporalmente. Considerando esse aspecto, embora o produto tenha sido projetado para ambiente doméstico, seu uso poderia ser estendido para instituições de longa permanência para idosos e hospitais, ampliando as possibilidades do projeto. Para trabalhos futuros, pretende-se aumentar a diversidade de mecanismos de interação com o produto e, assim, suas funcionalidades.

Entende-se, por fim, que a complexidade deste projeto não reside apenas nas questões técnicas do Design, mas também no emprego de estética adequada para atender aos desejos e às necessidades dos usuários com doença de Alzheimer em estágio leve especificamente. O desenvolvimento do dispensador eletrônico de medicamentos pretende oferecer, portanto, cuidado e independência a idosos com a condição e, acima de tudo, oportunidades de desenvolvimento cognitivo, a partir de um produto prático, interativo, com estrutura leve e resistente, de fácil manuseio e cuidadosamente projetado para não causar risco ao usuário. 


\title{
Referências
}

\begin{abstract}
ABRAZ - Associação Brasileira de Alzheimer. Cuidados com o doente de Alzheimer. Disponível em: < http://www.abraz.org.br/orientacao-a-cuidadores/cuidados-com-o-doente-dealzheimer>. Acesso em: 09 de ago. de 2016.
\end{abstract}

ABRAZ - Associação Brasileira de Alzheimer. Demência. Disponível em: < http://www.abraz.org.br/sobre-alzheimer/demencia >. Acesso em: 09 de ago. de 2016.

ABRAZ - Associação Brasileira de Alzheimer. O que é Alzheimer?. Disponível em: < http://abraz.org.br/sobre-alzheimer/o-que-e-alzheimer> acesso 09 de ago de 2016.

ABRAZ - Associação Brasileira de Alzheimer. Tratamento. Disponível em: < http://www.abraz.org.br/sobre-alzheimer/tratamento>. Acesso em: 09 de ago. de 2016.

ALZHEIMER MED. Fases e sintomas da doença. Disponível

em:<http://www.alzheimermed.com.br/diagnostico/sintomas-e-evolucao>. Acesso em: 20 ago. 2016.

ALZHEIMER ${ }^{e e}$ ASSOCIATION. Viagem ao cérebro. Disponível

em:<http://www.alz.org/brain_portuguese/02.asp>. Acesso em: 20 ago. 2016.

ASHBY, Michael, JOHNSON, Kara. Materiais e design: Arte e Ciência da seleção de materiais no design de produto. Rio de Janeiro: Elsevier, 2011.

BBC BRASIL. Número de idosos no Brasil vai quadruplicar até 2060 (2013). Disponível em: $<$ http://www.bbc.com/portuguese/noticias/2013/08/130829 demografia ibge populacao brasil lgb >. Acesso em: 09 de ago. de 2016.

BERTOLUCCI, Paulo Henrique Ferreira; OKAMOTO,Ivan Hideyo. Manual de Consulta - Doença de Alzheimer e outras demências. São Paulo: Lemos Editorial, 2003.

BONSIEPE, GUI E OUTROS. Metodologia Experimental: Desenho Industrial. Brasília: CNPq/Coordenação Editorial, 1986.

BROCK, J. D., BRUCE, R. F., \& REISER, S. L. (2009). Using Arduino for introductory programming courses. Journal of Computing Sciences in Colleges , 129-130.

CARAMELLI, P. e BARBOSA, M. T. (2002). Como diagnosticar as quatro causas mais frequentes de demência? Revista Brasileira de Psiquiatria, São Paulo , 24 (Supl I), 7-10. Disponpível em: <http://www.scielo.br/pdf/rbp/v24s1/8850.pdf>. Acesso em: 09 de ago. de 2016.

CUIDAR DE IDOSOS. Manual Do Cuidador Alzheimer. Disponível

em:<http://www.cuidardeidosos.com.br/manual-do-cuidador-alzheimer/>. Acesso em: 22 de ago. 2016.

FREITAS, E.V., SILVA, M.C.A. Hipertensão arterial no idoso. In: Sociedade Brasileira de Geriatria e Gerontologia; Kitner D, Jaluul O, organizadores. PROGER Programa de Atualização em Geriatria e Gerontologia: Ciclo 1. Porto Alegre: Artmed Panamericana; 2015. p. 31-66. (Sistema de Educação Continuada a Distância, v.1)

GIL, Antonio Carlos. Como Elaborar Projetos de Pesquisa. 5ํEd. São Paulo. Atlas, 2010.

GIULIANO C. P. Cultural Affordance no Design de Produtos. In: X SEPesq - SEMANA DE EXTENSÃO, PESQUISA E PÓS-GRADUAÇÃO, 2014, Porto Alegre: Centro Universitário Ritter dos Reis, Anais eletrônicos. Porto Alegre: UniRitter, 2014. 
Hora do medicamento. Aplicativo. Disponível em <https:/itunes.apple.com/br/app/hora-domedicamento-lembretes/id863327251?mt=8>. Acesso em: 15 nov. 2016.

IBGE - Instituto Brasileiro de Geografia e Estatística - Perfil dos Idosos Responsáveis pelos Domicílios (2002). Disponível em:

<http://www.ibge.gov.br/home/presidencia/noticias/25072002pidoso.shtm> >. Acesso em: 09 de ago. de 2016.

IDEO. HCD - Human Centre Design: Kit de ferramentas. EUA: Ideo, 2009. 102p.

IIDA, ITIRO. Ergonomia: projeto de produção. São Paulo : Editora Edgard Blücher, 2010. 2.ed.

KUNZLER, Lizandra Stechman Quintana. Estudo das variáveis de rugosidade, dureza e condutividade térmica aplicado à percepção tátil. 2003. 120p. Dissertação Mestrado. (Engenharia de Materiais). Universidade Federal do Rio Grande do Sul, Porto Alegre. Disponível em < http://hdl.handle.net/10183/4004 >. Acesso em: 15 nov. 2016.

LESKO, Jim. Design Industrial: Materiais e Processo de Fabricação. Tradução Kindler Júnior, Clovis Belbute Peres, São Paulo: Blucher, 2004.

LÖBACH, Bernd. Design industrial: bases para a configuração dos produtos industriais. São Paulo: E. Blucher, 2001.

MANZINI, Ezio; VEZZOLI, Carlo. O desenvolvimento de produtos sustentáveis: os requisitos ambientais dos produtos industriais. 1. Ed. São Paulo: Editora

NORMANN, Donald A. Design Emocional: Por que adoramos (ou detestamos) os objetos do diaa-dia. Rio de Janeiro: Rocco, 2008

PANERO, Julius; ZELNIK, Martin. Dimensionamento humano para espaços interiores: um livro de consulta e referência para projetos. Barcelona, España: Gustavo Gili, c2002. 320 p.

PAZMINO, Ana Verônica. Como se cria. São Paulo. Bluher, 2013

PRECCE,Jennifer; ROGERS, Yvonne, SHARP, Helen,. Design de interação: além da interação homem-computador. Traduzido por: Viviane Possamai. Porto Alegre: Bookman, 2005. 2.ed. São Paulo: Edgard Blücher, 1998. 260 p. 